\title{
openheart Exercise prescription in young children with congenital heart disease: time for a change in culture
}

\author{
Graham Stuart (D) , ${ }^{1,2}$ Lynsey Forsythe ${ }^{1}$
}

To cite: Stuart G, Forsythe L. Exercise prescription in young children with congenital heart disease: time for a change in culture. Open Heart 2021;8:e001669. doi:10.1136/ openhrt-2021-001669

Accepted 17 May 2021

\section{SLinked}

- http://dx.doi.org/10.1136/ openhrt-2021-001599

Check for updates

(C) Author(s) (or their employer(s)) 2021. Re-use permitted under CC BY-NC. No commercial re-use. See rights and permissions. Published by BMJ.

${ }^{1}$ Cardiology, Bristol Royal Hospital for Children, Bristol, UK ${ }^{2}$ Department of Clinical Sciences, University of Bristol, Bristol, UK

Correspondence to Dr Graham Stuart; graham. stuart@nhs.net
The outcome for children born with congenital heart disease (CHD) has been transformed over the last 50 years. Largely as a consequence of advances in surgical and transcatheter intervention, the majority of children with even the most severe forms of CHD are likely to reach adult life. ${ }^{1}$ Indeed, there are now considerably more adults with CHD than children. ${ }^{2}$ As we witness this rise in the number of adults with CHD we need to turn our attention to improving not just longevity but also quality of life.

In the past, most children with CHD were discouraged from taking part in regular exercise. There were many reasons for this. Perhaps the most common was a belief in the family, often mirrored by the supervising clinician, that strenuous exercise was potentially dangerous and could lead to clinical deterioration or even a fatality. Another important reason was the poor understanding of exercise physiology in the cardiology community and the failure to recognise the importance of exercise in maintaining good general and cardiovascular health.

Many studies have now demonstrated that a short-term exercise prescription can improve general, cardiovascular and mental health in older children and adults with CHD. ${ }^{3-7}$ These benefits extend beyond a simple improvement in exercise capacity and include improved feelings of physical self-perception and satisfaction with life. ${ }^{6}$ Moreover, the risk of clinical deterioration or sudden death during an exercise programme is extremely small. ${ }^{8}$ In 2013, the American Heart Association recommended that all older children and young adults with CHD receive counselling to encourage daily participation in physical activity as a core component of every patient encounter. ${ }^{9}$ Recent consensus guidelines have supported this and encourage a personalised exercise prescription to be given to all teenagers and young adults with CHD. ${ }^{10}{ }^{11}$ Until now, however, very few data have been available to guide exercise prescription in younger children with CHD.

In the paper by Callaghan, the authors conducted a randomised clinical trial of exercise training in a cohort of 163 young children (5-10years old) with CHD. ${ }^{12}$ This is the first large study to look at exercise prescription in the primary school age child with CHD and is the largest randomised controlled trial of an exercise intervention in children of any age. Using procedures that can easily be performed in the outpatient clinic, the authors build on their previous exercise intervention study in adolescents with CHD. ${ }^{12}$ They used a waist-worn accelerometer to monitor baseline activity, an exercise ECG stress test to assess exercise capacity and a questionnaire to assess daily activities. The intervention group attended an educational day in which they participated in a psychologist-led motivational group discussion. They were also given dietary advice and were provided with an exercise information pack and a personalised exercise advice plan. A copy of the exercise plan was sent to the participants' school and families were encouraged to communicate with the research fellow during the 4-month intervention period. A repeat baseline assessment was then carried out. The control group received the 'usual' level of paediatric cardiology care. The study group was found to be within $\pm 2 \mathrm{SD}$ of the mean for UK growth reference data. The authors do not comment on the prevalence of obesity but others have found obesity to occur in as many as $27 \%$ of CHD children-similar to that in the normal population. ${ }^{13}$ The treatment group was found to have significantly increased their exercise duration and power output on the exercise stress test. This was by a relatively small amount with an estimated effect size of only around $0.7 \mathrm{~min}$ and $6 \mathrm{~W}$. However, the principle was established that this level of exercise intervention in young children can have an effect after 4 months which is both measurable and if continued may be of clinical significance. 
Interestingly, the step count showed a trend to increase in the treatment group which was not statistically significant. However, this does highlight the limitations of accelerometry which would not register a change in children whose main activity, for example, was cycling or swimming.

This study is limited in that it uses outcome measures (exercise time completed on a exercise bicycle and accelerometer derived activity counts using an accelerometer) which are simple but incomplete. Thus, for example, full cardiopulmonary exercise testing might have been more informative. The authors have taken a pragmatic approach which does have merits in terms of compliance-particularly in the younger child. Moreover, the relative lack of increase in accelerometry counts may reflect the local expertise. These were children who were being managed in a unit with a commitment to encouraging exercise. Sadly, this is not a commitment seen in all congenital heart centres. Although, there was no index of well-being assessed in the children, motivational interviewing during the study had a positive effect on parental attitudes to exercise as assessed by the readiness rating rulers before and after the education day. Opportunities for parental interaction with the research team were judged as an important aspect of the intervention by the authors.

A further limitation of the study was the exclusion of children with syndromes in the study. While including children with learning difficulties might make the exercise intervention more complex, reduced strength and aerobic capacity in patients with learning difficulties (eg, Down syndrome) can limit their ability to perform tasks of daily living. ${ }^{14}$

Thus, improved physical fitness may have important benefits to CHD patients with learning difficulties.

This is an important study as it demonstrates that the benefits of exercise prescription seen in teenagers and adults with CHD do seem to translate to the younger child. There are, however, some important caveats. The improvements are small and crucially, we do not know if this benefit continues outside of the immediate study period. This is perhaps the biggest flaw in most of the short-term exercise prescription studies in CHD. What is needed is a much larger, multicentre, long-term study to see if these benefits can be maintained and if they translate into long-term physical, cardiovascular and well-being benefit for the child. There are some clues that this may be the case. Thus, in an editorial comment on one of the largest, long-term outcome studies of the Fontan procedure, d'Udekem noted that the best predictor of outcome was the amount of physical activity participated in by the patient. ${ }^{15}$ In addition to the need for a long-term outcome studies of exercise prescription in CHD, we need to address the issue of clinician education. Most clinician have a poor understanding of exercise physiology in general and the cardiovascular benefits of exercise in patients with chronic conditions including CHD. This should be addressed both in the medical school curriculum and during postgraduate training. This will require a culture change from diagnosis and treatment of illness to improvement of health. This is long overdue.
Twitter Graham Stuart @ag_stuart

Contributors GS was the main author and drafted the article and reviewed the Callaghan paper. LF reviewed the Callaghan paper and commented on and contributed to the editorial.

Funding An Evaluation of a Physical Activity and Exercise Promotion Pathway for Patients With Congenital Heart Disease Translational research project grant Heart Research UK $2018 £ 101994$.

Competing interests None declared.

Patient consent for publication Not required.

Provenance and peer review Commissioned; internally peer reviewed.

Open access This is an open access article distributed in accordance with the Creative Commons Attribution Non Commercial (CC BY-NC 4.0) license, which permits others to distribute, remix, adapt, build upon this work non-commercially, and license their derivative works on different terms, provided the original work is properly cited, appropriate credit is given, any changes made indicated, and the use is non-commercial. See: http://creativecommons.org/licenses/by-nc/4.0/.

ORCID iD

Graham Stuart http://orcid.org/0000-0003-2789-2216

\section{REFERENCES}

1 Mazor Dray E, Marelli AJ. Adult congenital heart disease: scope of the problem. Cardiol Clin 2015;33:503-12. vii.

2 Marelli AJ, lonescu-Ittu R, Mackie AS, et al. Lifetime prevalence of congenital heart disease in the general population from 2000 to 2010. Circulation 2014;130:749-56.

3 Pieles GE, Horn R, Williams CA, et al. Paediatric exercise training in prevention and treatment. Arch Dis Child 2014;99:380-5.

4 Williams CA, Wadey C, Pieles G, et al. Physical activity interventions for people with congenital heart disease. Cochrane Database Syst Rev 2020;10:CD013400.

5 van Deutekom AW, Lewandowski AJ. Physical activity modification in youth with congenital heart disease: a comprehensive narrative review. Pediatr Res 2020. doi:10.1038/s41390-020-01194-8. [Epub ahead of print: 13 Oct 2020].

6 Dua JS, Cooper AR, Fox KR, et al. Exercise training in adults with congenital heart disease: feasibility and benefits. Int $\mathrm{J}$ Cardiol 2010;138:196-205

7 Morrison ML, Sands AJ, McCusker CG, et al. Exercise training improves activity in adolescents with congenital heart disease. Heart 2013;99:1122-8.

8 Duppen N, Takken T, Hopman MTE, et al. Systematic review of the effects of physical exercise training programmes in children and young adults with congenital heart disease. Int J Cardiol 2013;168:1779-87.

9 Longmuir PE, Brothers JA, de Ferranti SD, et al. Promotion of physical activity for children and adults with congenital heart disease: a scientific statement from the American Heart Association. Circulation 2013;127:2147-59.

10 Budts W, Pieles GE, Roos-Hesselink JW, et al. Recommendations for participation in competitive sport in adolescent and adult athletes with Congenital Heart Disease (CHD): position statement of the Sports Cardiology \& Exercise Section of the European Association of Preventive Cardiology (EAPC), the European Society of Cardiology (ESC) Working Group on Adult Congenital Heart Disease and the Sports Cardiology, Physical Activity and Prevention Working Group of the Association for European Paediatric and Congenital Cardiology (AEPC). Eur Heart J 2020;41:4191-9.

11 Pelliccia A, Sharma S, Gati S, et al. 2020 ESC guidelines on sports cardiology and exercise in patients with cardiovascular disease. Eur Heart J 2021;42:17-96.

12 Callaghan S, Morrison ML, McKeown PP, et al. Exercise prescription improves exercise tolerance in young children with CHD: a randomised clinical trial. Open Heart 2021;8:e001599.

13 Barbiero SM, D'Azevedo Sica C, Schuh DS, et al. Overweight and obesity in children with congenital heart disease: combination of risks for the future? BMC Pediatr 2014;14:271.

14 Cowley PM, Ploutz-Snyder LL, Baynard T, et al. Physical fitness predicts functional tasks in individuals with Down syndrome. Med Sci Sports Exerc 2010;42:388-93.

15 d'Udekem Y, Fitness C. Not the severity of the condition, dictates late outcomes after Fontan procedures. J Am Coll Cardiol 2017;69:2745-7. 